\title{
Management and Human Factors: Exploratory Research with Focus Groups
}

\author{
di Cinzia Novara ${ }^{1}$, Gioacchino Lavanco ${ }^{1}$, Giuseppe Mannino ${ }^{2}$ e Consuelo Serio ${ }^{1}$
}

\begin{abstract}
The paper analyses the training needs of managers belonging to public and private companies in the Region of Sicily (Italy), using focus groups. 52 managers took part in the research, 32 executives and 20 employees with intermediate positions in collaboration with senior management. This is a qualitative research with explorative purposes whose approach is part of the symbolic interactionism paradigm. Data analysis, supported by the Atlas.ti software, have permitted to code the meanings underlying the text of the narratives and identifying four "codes families" as key themes of the observed reality. It emerges a managerial profile that moving between critical and resources, shows an awareness of the need to refine skills that take into account the human factor, semantic category that is present across all the thematic areas addressed and on which should think and plan a specific management training.
\end{abstract}

Keywords Management, Human Factor, Training, Focus group, Qualitative research

\section{Introduction}

Company Management now demands higher quality in terms of skills, strategic vision, role awareness and development strategies that look to of the health's manager as a precondition of healthy organizations (Campbell Quick, et al., 2000; Gullo, et al., 2015). Patterns aimed to the human factor, whose object of study is merely the subject of knowledge itself (Novara and Lavanco, 2008), are embedded to the concept of the reflexivity. Similarly, training identifies a beneficiary which is also the conductor of training towards who provides it. It refers to a formation that means change (Cummings e Worley, 2013; Novara et al., 2017) throughout life, knowledge and experience, and which ends up involving the individual in its singularity and subjectivity (Mannino et al., 2017; Mannino \& Caronia, 2017). The result is a flexible training model from which everyone draws what they need, a critical one, because they have learned to adjust and adapt to the life context and finally the human training, i.e. attentive to personal variables and responsive to the special educational needs (Venza et al., 2007; Mannino \& Faraci, 2017).

The present study stems from a commission by the $\mathrm{SDI}^{3}$ which, in collaboration with the teaching Community Psychology at the University of Palermo, captures the training challenges on a human scale, requiring an investigation to be carried out into the training needs of managers, of public and private companies, in the Region of Sicily.

In particular, in this paper we will refer to research on focus groups as a proportion of qualitative research in exploratory purposes (Morgan \& Krueger, 1998; Morgan, 1997; Krueger, 1994; Merton, Fiske \& Kendall, 1990). In social research, in fact, this technique has been widely applied, especially in those disciplines interested in understanding complex situations where the role played by the context itself becomes a variable key in interpreting the data collected (CooperThomas \& Wright, 2013; Mannino et al., 2015; Mannino \& Giunta, 2015). Looking at the literally vast panorama present on the subject of management (Matzler et al., 2015; Avolio et al., 2009; Dulewicz \& Higgs, 2005) it is now established that the "human" factor is a fundamental requirement of the management-oriented to effective organization. Moreover, in psychological

\footnotetext{
${ }^{1}$ University of Palermo.

${ }^{2}$ Lumsa - Free University Maria SS. Assunta, Roma

${ }^{3}$ The SDI is a consultancy specialising in knowledge management and technology that can reflect on-going management and provide innovative design guidelines for businesses, based on an analysis of staff needs.
} 
leadership research, it becomes increasingly important to understand how the specificity of the organizational and territorial contexts influence the leadership (Liden \& Antonakis, 2009; Sparrowe, 2014) and how much, instead, can be considered "transversal" to the different contexts and, therefore, useful to understand in terms of best practices. It also adds the propensity of some disciplines to privilege as partners people who face daily experiences and problems and who become the subject of analysis and investigation on the part of the researcher, therefore, interested in collecting qualitative data and narratives that unfold in interactive contexts, thus explaining specific feelings and behaviours within the context (Silverman, 2013; Pellerone et al., 2016).

With regard to the co-operation requested by the SDI, the analysis of demand has justified an investigation, as demand is the proponent, the body trainer, both potential beneficiaries and the managers in training. It has defined the investigation both as a moment of reflection of the SDI on the methods and the content which had led, up to that moment, to the provision of training, as well as exploration and acceptance of a new demand for training on the part of managers.

\section{Exploratory Research with Corporate Executives}

In the light of the objective shared with the client, a series of focus groups were proposed:

1. groups of managers only, both with and without any training experience;

2. groups of managers and transitional roles in cooperation with management.

A total of 40 Sicilian companies from Palermo, Catania, Trapani and Agrigento and specialised in various types of activities (the field of municipal utilities, waste collection, training and communication) were contacted to participate in the research; they participated in the focus groups with a total of 52 people, 32 managers and 20 employees who hold intermediate positions in collaboration with senior management. The subjects involved were between 34 and 62 years of age (the mean age was 45 years), held a degree $(n=41)$, had graduated from secondary school with the equivalent of A-Levels $(n=11)$, and were mostly male $(n=38)$.

The groups extent is that of the mini group (Greenbaum, 1998) having covered a range between 5-7 participants per group. The decision was prompted by a desire to put each participant in a position to have as much time to present their considerations, in view of the complexity of the proposed activity and the likely involvement of the participants who did anticipate, therefore, a longer time for debate (Zammuner, 2003). Recruitment was managed directly by the SDI using time included in a lunch break as an incentive, so as not to hinder any of the managers' work commitments and to offer them lunch at the end of each focus group. The lunch break was also an opportunity to break the ice, immediately creating a friendly and welcoming atmosphere. The place that hosted the meetings was not close to their places of work, although it was for the managers involved, and was a common point for professional meetings.

On average, the duration of the focus groups was 90 minutes.

The table of questions submitted to the groups can be attributed to the questioning route method, a rather structured format that is, on the one hand, likely to soften the spontaneity of the discussion, but on the other hand, guarantees a comparison between the responses of the participants; in the specific case of our study, this methodological framework was crucial in addressing the heterogeneity between and within groups, whilst linking consistent and non chaotic data to the research objectives (Table 1). The mode of conduct was, for this reason, rather directive and supported by the observation of an verbalizing assistant. 


\begin{tabular}{l|l}
\hline \multicolumn{1}{c|}{\begin{tabular}{c}
\multicolumn{1}{c}{ TYPE OF } \\
QUESTION
\end{tabular}} & \multicolumn{1}{c}{ QUESTIONS } \\
\hline $\begin{array}{l}\text { Ice-breaker } \\
\text { Questions }\end{array}$ & $\begin{array}{l}\text { What do you do in life (your professional role), and for how } \\
\text { many years have you held this role? }\end{array}$ \\
\hline $\begin{array}{l}\text { Introductory } \\
\text { Question }\end{array}$ & $\begin{array}{l}\text { We try to gage the Manager's profile: what are, in everyone's } \\
\text { opinion, the characteristics of the manager (his skills, his } \\
\text { knowledge, his qualities, his flaws)? }\end{array}$ \\
\hline \multirow{5}{*}{$\begin{array}{l}\text { Transitional } \\
\text { Questions }\end{array}$} & $\begin{array}{l}\text { What are the critical situations that a manager should be } \\
\text { prepared to face? } \\
\text { - Give a few examples of a critical event which you have } \\
\text { come across? } \\
\text { - Which skills did you exercise to overcome this } \\
\text { situation? }\end{array}$ \\
\cline { 2 - 2 } $\begin{array}{l}\text { Significant } \\
\text { Questions } \\
\text { proud) and which skills have you used to achieve that result? }\end{array}$ & $\begin{array}{l}\text { What should give you management training? } \\
\text { Some of you have no other training experiences } \\
\text { - Those of you who have done some training, what would you } \\
\text { advise others who have not already done any training? And } \\
\text { vice versa, those without any training experience behind them, } \\
\text { what would you like to ask those who have done some } \\
\text { training? } \\
\text { - For those who have had some training: name some positive } \\
\text { and negative aspects. } \\
\text { - Who will be next to do it: expectations }\end{array}$ \\
\hline $\begin{array}{l}\text { What colour is leadership? If we were to use a metaphor, you } \\
\text { could say that "Leadership is the colour ...." }\end{array}$ \\
\hline Closing Question
\end{tabular}

\section{Results}

The approach used for data analysis is attributed here to the qualitative analysis that is deeply rooted in the symbolic interactionism perspective (Corbin \& Strauss, 2008; Chamberlain-Salaun et al., 2013). This aims to understand a range of opinions on the topic discussed, as well as the meanings that underlie the narratives which identify the possibility of arriving at a key to understanding and interpreting the observed reality, by virtue of the relationships between the categories of meaning which emerge from the research. In our study, this step was assisted by Atlas.ti software (7.0 version, Muhr, 1997) which, based on the principles of Grounded Theory (Glauser \& Strauss, 1967; Charmaz, 2006), organizes data according to a network model.

Specially, in order to analyze textual materials (obtained by typing out what has been said by focus group) a code is assigned to pieces of a selected part of the track as more interesting for the research. During this process, the research team proceeds to create wider meaning categories, putting together the codes with the same conceptual core and creating code families.

Overall, 35 codes and 4 code families have been identified through the level of agreement between two independent judges who have us allowed to evaluate comprehensiveness and mutual exclusivity among them.

The first map is the profile of the 'manager type' and is clear from the discussions in focus groups (Map 1). Participants define the "manager type" as a precursor and as someone who can "acknowledge signals" and advances compared to the present, and is able to "look forward and beyond", since he owns a design expertise that allows him to 'provide incentives' to other employees. This almost prophetic image of the manager is well rendered by the quote from one of 
the participants: «Do you know why my father was lucky and yours was not? Because where your father saw a field full of stones, my father saw a field full of roses ...»

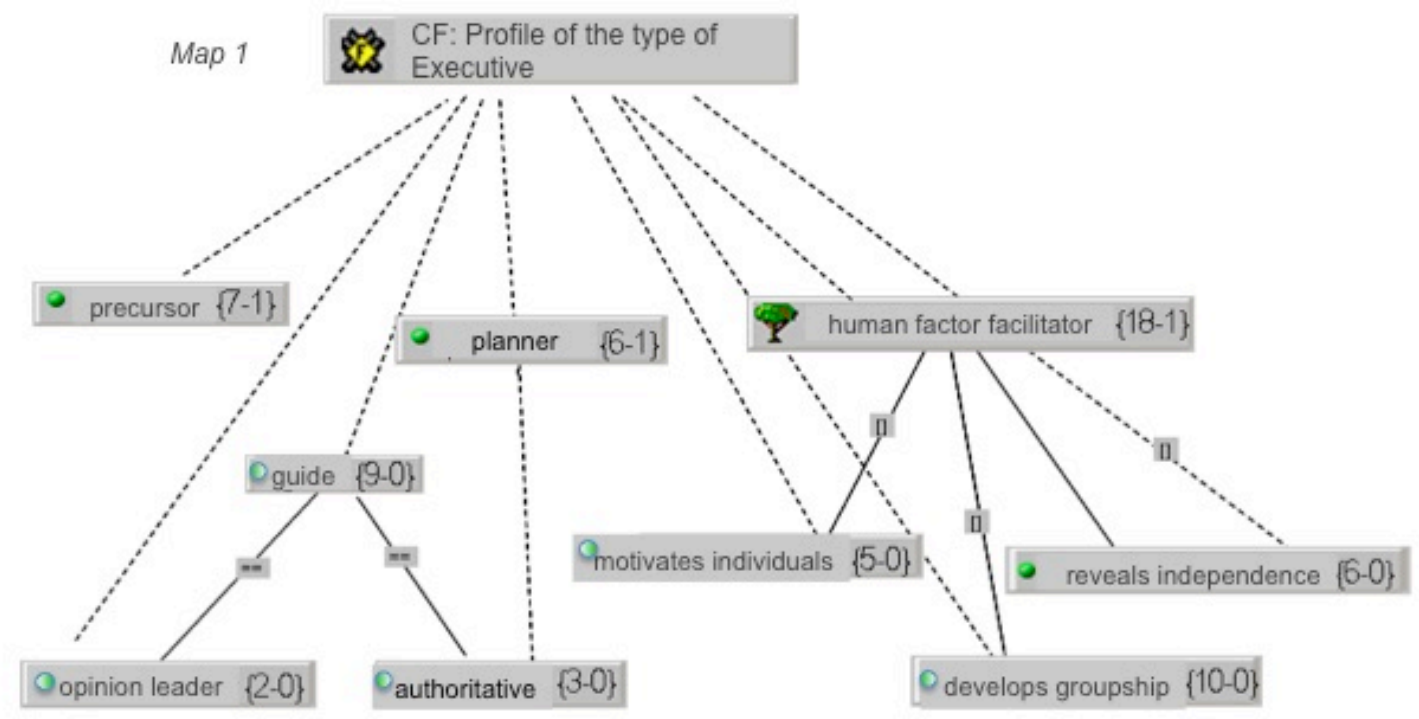

In this aspect, alongside more specific 'technical skills' that give us an executive planner, is one who knows 'how to manage time and space' and 'how to plan activities' in the short term, in order to do the job in an efficient way. The codes that define leadership and the facilitator of human factors are significant in terms of occurrences. In the first case, it expressly refers to a guide similar to a 'coach' or a 'conductor', as opinion leaders who are able to influence the moods and the results of the team, therefore expressing a role but maintaining a leading and authoritative behaviour and showing an 'aptitude to democratic control'.

The most characteristic aspect of the manager type is, however, what we may see on the right side of Map 1. The role of the Human Factor Facilitator seems to focus on employees as people before professionals, so it is primarily called managing relationships. Of this competence, individuals' motivation plays a part as individuals are, therefore, 'heard' even when they do not communicate visibly and they are encouraged to develop an association with respect to the organization; always being part of the human factor it is the ability to develop groupship (like being part of a whole group) from the differences in roles and responsibilities of each other that are brought to light as they make a well-matched team, if only in respect of these differences.

Finally, still within the management of the human factor, we find the "comparison with all those you work with' in an attitude of collective learning that in the name of a recognized interdependence between the parties (Moscato et al., 2016) to say face-to-face to the leaders themselves, 'is one from which one can learn'.

It is evident that the portrait of this manager seems flawless, which is why the conductor, during the group discussion, focused on this point and wondered if the ruling can be considered free from any 'defects in the role'. 


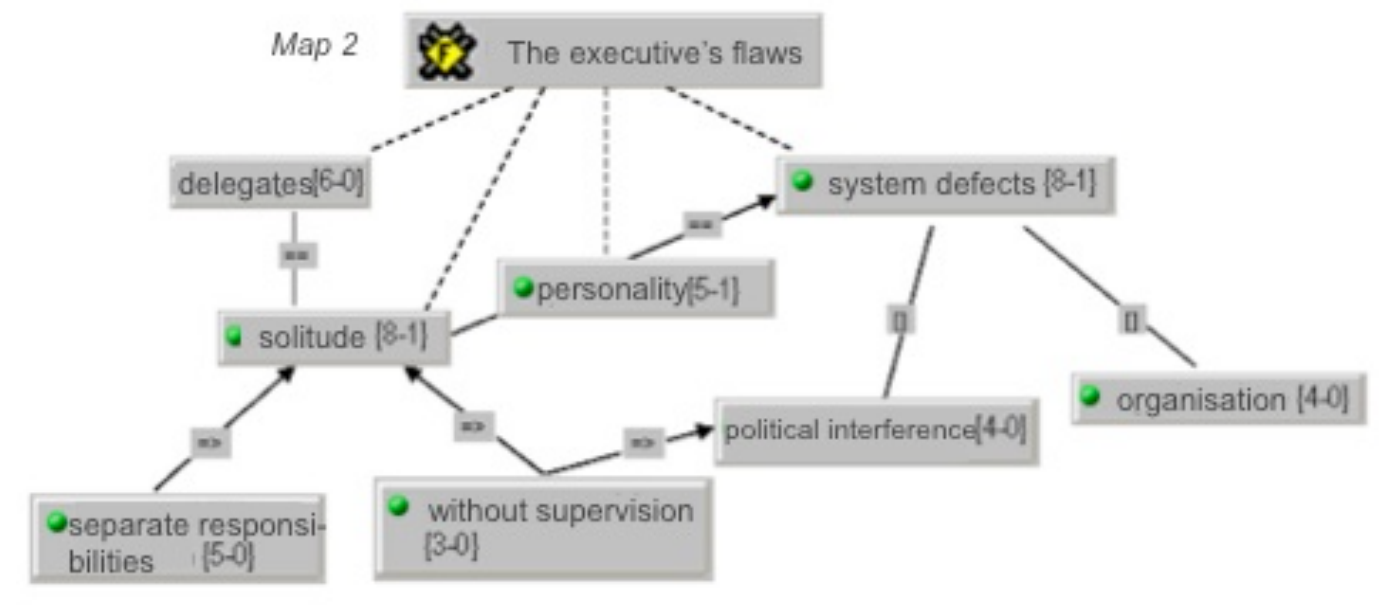

Map 2 exemplifies those personal or role playing defects by providing a caricature of the manager. What, more obviously, undermines the position of the perfect Manager is the experience of loneliness, associated too much or too little with the dilemma of the delegate that in both cases can produce errors of assessment: in other words, a manager overloaded with commitments of which he is unable to fulfill or an excessive delegation to collaborators. One participant, citing the text of Blanchard (2002), recalls that he was surprised when he discovered that the main manager of the book «was perfectly free and so good at delegating that things were being done by themselves».

This sense of loneliness - indicated yet as a risk factor in other studies (Campbell Quick et al., 2000) - strongly affects the responsibility not shared with middle management or above and the absence of supervision so that executives feel, at times, 'adrift' and maintain that 'without any feedback you can fail'. Everything here tells the importance of a monitoring system for the other executive positions, as has been confirmed in many financial fields (Cornelli et al., 2013). Again, while respecting the roles, collaboration with others is vital, even when it comes to making important decisions.

It is thought that personality characteristics in defining the defects of leadership occupy a small corner, by referring, for example, to impulsivity, superficiality in 'underestimating or overestimating a problem', or the lack of optimism and determination 'that are expressed in the inability to see' an opportunity behind a problem. Almost like a game of mirrors, yet another interesting aspect emerges in conceiving the defects of the manager, as flaws in the system highlight relationships between politics, business and markets.

This combination is different in the case of a public or a private company, especially in the first case, where it is clear that political interference by reducing the autonomy of the manager 'brings out the bad character'. They are part of defects of the system, ultimately, as well as aspects of the organisation which we could attribute to an inconsistent organisational culture, where parts and the whole of it are not moving towards the same goals.

Map 3 shows, in a composite way, what the participants classify as "a critical event" and, conversely, which solutions you need to practice to be able to cope. Critical events have been derived from field experiences that executives will have faced in the course of their careers and which have been retold in group discussions, by enabling an honest comparison between the participants, beneficial, according to everyone, to further enrich any experiential baggage. 


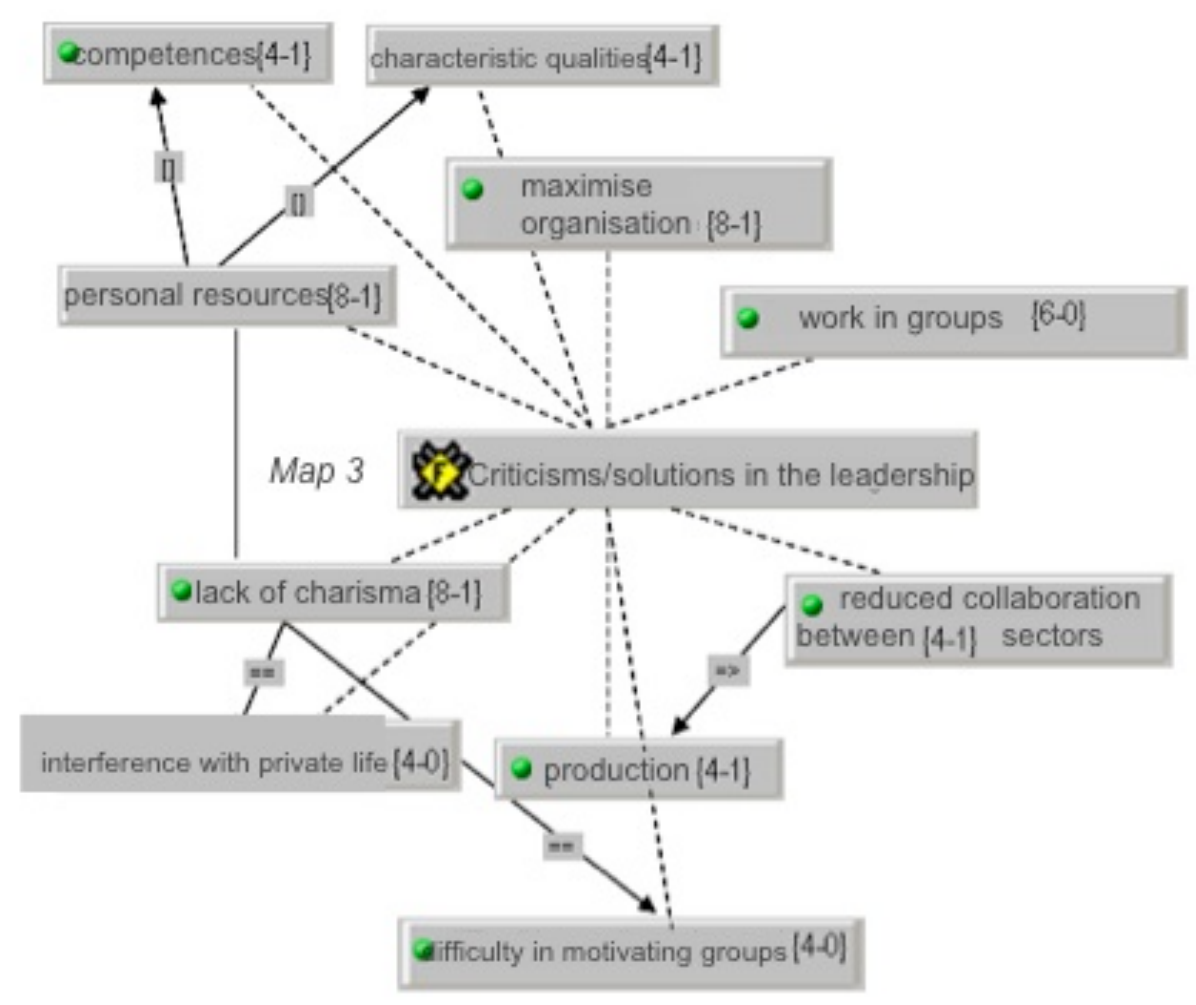

Critical issues and solutions seem to amalgamate as a single semantic map in which we find the critical illustrated in the lower part, and possible solutions in the upper part of the graph (Map 3). Therefore a critical event can be related to the production if this is aligned to high standards. In the event of this, however, it adversely affects the limited cooperation between sectors (for example, the technical and the organisational) but can, however, find a solution if you look to optimise the organisation. This expression means that participants have to 'rationalize tasks' and 'improve vertical and horizontal lines of communication', both on a micro and macro level (i.e. between individuals and departments), 'to invest in training' for all members of the company, conveying tasks and efforts on common and shared goals.

Another critical area is the absence of charisma that is, from seeing it falter, in some circumstances thought to be the guide and driver of the group, also coinciding with personal issues pertaining to the privacy of the manager, the fact that life that is not always possible to keep away from the office and is affected, thereby influencing job performance. The lack of charisma that is associated with the difficulty to motivate groups can be fixed by focusing on the 'human and communicative factor' which highlights how are important the 'group collaboration' and 'to work together', sharing tasks and 'drawing on all personal resources'. In this case, personal resources represent the map code in itself, since they include both the personal qualities such as assertiveness and determination in advancing the company, as well as the technical, organisational and communicative skills acquired directly in the field of employment.

Map 4 gathers the considerations of the executives regarding their training needs, who in retrospect are consistent with the image of managers that, together with management techniques and strategies of the trade, aim to ripen those transversal skills that are resource in coping with personal difficulties as well as work difficulties. 


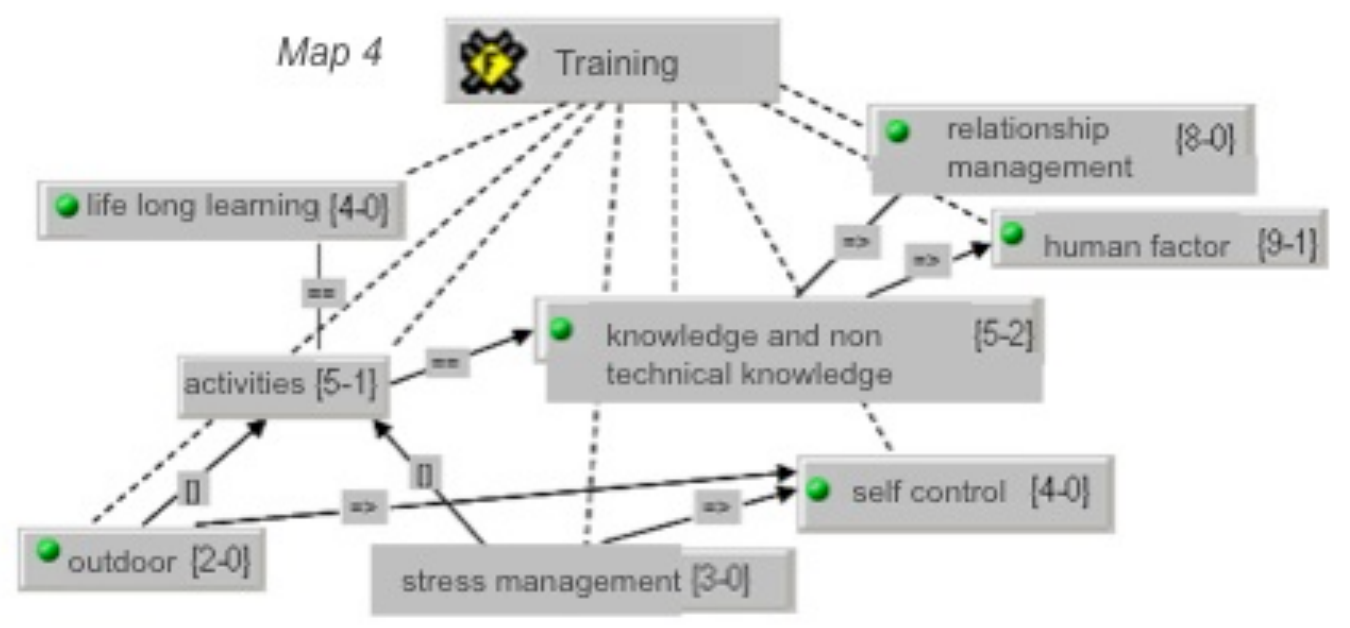

The training model that participants say they marry is that of life-long learning, something that affirms the right to education as non-depleting for an adult of a certain age and outlines the complementary nature between the right to education and the right to work, between learning in formal and informal contexts. The model is, in fact, associated with activities and training content that recall the recognition of the person as a whole, not only as a container of technical skills related to areas of knowledge, but also transversal skills to contextualize, creatively, in life and in work. The outdoors and techniques of stress management are some examples of training activities aimed at improving "mutual reliance" and self-control. Such activities are associated with technical knowledge and non technical knowledge that involve a greater knowledge and relationship management, especially those aimed at teamwork and conflict management, and more general human factors where listening, observing, empathy and communication must 'grow' because - as recalled by the participants themselves - 'the company is made up of people'.

\section{Discussion}

The results provide a list of priorities that can be summarized in four points:

- according to Mannino, Schiera (2017) and Mannino et al., (2017) in clinical field, research participants consider the human factor, in all its facets, to influence organizational personal skills.

- training needs are expressed strongly in this direction and can be linked to content and activities that disregard indoctrination on management, suggesting wider training on a human scale; - the element of leadership would seem central to the role of authoritative guidance that the executive sums up, while considering the management of power, as well as passive learning, mostly in relation to the personality of the individuals;

- the critical event which the manager can encounter is seen as an event all round with respective solutions; this aspect, on the one hand, reveals a linear thinking that moves based on semantically opposite and complementary concepts (absence / present teamwork, absence / present personal qualities, etc.), on the other hand, it could refer to a specific mode of problem solving for the executive who - as formulated by the participants - must be able to see 'an opportunity behind a problem' (cfr. par. 4), meaning every situation is potentially educational.

The first line is build following a training model focused on the knowledge transformation (Novara et al., 2017) to address a possible change, first from the movements of knowledge itself.

Consideration, finally, must be given to the content revealed by our study and its ability to have an impact on management training. As part of the action research, we cannot assume that it is just 
enough to identify symptoms to operate treatment (Novara et al., 2016a); rather, the information presented is the exploratory research offering the ability to rethink and plan research in the future. If we assume the idea that knowledge is not the discovery but the invention (Samson, 1999), since it does not lead to something previously that existed, we can understand the value of the research with focus groups and its implication on the service offers towards the territory (Novara et al., 2016b). Even the metaphors used in the closing by our participants ${ }^{4}$ are metaphors that strongly show the desire to leave the dark period that the world economy is going through, using it as a primary responsibility of management to cope with the unpredictability of events by creatively recombining old and new skills, personal and group skills, as well as character and organizational aspects.

\section{Limitations}

Surely, the present research is not free from restrictions.

We focused on the self-perceptions of individuals within the organization but it was not possible to analyze other important variables in this context. Our research was deliberately exploratory but the results raise a number of interesting questions that merit further investigation. A more systematic analysis would be advisable in regards to how relationships between managers and employees are implicated in the development of perceptions of management and organizational events. The research could also compare organizations of different types and different cultures to see if there are differences in the perception of management and training needs.

\section{References}

Avolio, B., Walumbwa, F. \& Weber, T. J. (2009). Leadership: Current Theories, Research, and Future Directions. Management Department Faculty Publications. Paper 37. http://digitalcommons.unl.edu/managementfacpub/37

Campbell Quick, J., Gavin, J. H., Cooper, C. L., Quick J. D. \& Gilbert R. E. (2000). Executive Health: Building Strength, Managing Risks [and Executive Commentary]. The Academy of Management Executive (1993-2005), 14 (2), (May, 2000), 34-46.

Chamberlain-Salaun J., Mills J., \& Usher K. (2013). Linking Symbolic Interactionism and Grounded Theory Methods in a Research Design: From Corbin and Strauss "Assumptions to Action. SAGE, 3, 1 -10. doi: $10.1177 / 2158244013505757$

Charmaz, K. (2006). Constructing Grounded Theory. A practical Guide through Qualitative Analisys. London: Sage.

Cooper-Thomas, H.D. \& Wright, S. (2013). Person - environment misfit: the neglected role of social context. Journal of Managerial Psychology, 28, 1, 21-37.

Corbin, J. \& Strauss A., (2008). Basics of qualitative research: Techniques and procedures for developing grounded theory. Los Angeles: Sage.

Cornelli, F., Kominek, Z. \& Ljungqvist, A. (2013). Monitoring Managers: Does It Matter? The Journal of Finance, 68 (2) (april 2013), 431-481.

Cummings, T. G. \& Worley, C. G. (2013). Organizational, Development \& Change. Stamford, CT: Cengage Learning.

Sparrowe, R. T. (2014). Leadership and Social Networks: Initiating a Different Dialog. In D.V. Day (Ed.). The Oxford Handbook of Leadership and Organizations. Oxford: University Press.

\footnotetext{
4 "Green, a beautiful green, alive but peaceful"; "... the blue ..... of a blaring sky; an orange expressing heat, etc ...
} 
Dulewicz, V. \& Higgs M. (2005). Assessing leadership styles and organisational context. Journal of Managerial Psychology, 20(2), 105-123.

Gervasi, A., La Marca, L., Lombardo, E., Mannino, G., Iacolino, C. \& Schimmenti, A. (2017) Maladaptive personality traits and internet addiction symptoms among young adults: a study based on the alternative dsm-5 model for personality desorders. Clinical neuropsychiatry, 14 -1, 2-28.

Glaser, B. G. \& Strauss, A. L. (1967). The Discovery of Grounded Theory: Strategies for Qualitative Research. Chicago: Aldine.

Granieri, A., La Marca, L., Mannino, G., Giunta, S., Guglielmucci, F. \& Schimmenti, A. (2017). The Relationship between Defense Patterns and DSM-5 Maladaptive Personality Domains. FRONTIERS IN PSYCHOLOGY, 8, 1-12, ISSN: 1664-1078, doi: 10.3389/fpsyg.2017.01926

Greenbaum, T.L. (1998). The Handbook For Focus Group Research $\left(2^{\text {nd }}\right.$ ed.). London: Sage.

Gullo, S., Lo Coco, G., Di Fratello, C., Giannone, F., Mannino, G. \& Burlingame, G. (2015). Group Climate, Cohesion, and Curative Climate: A Study on the Common Factors in the Group Process and Their Relation with Members' Attachment Dimensions. RESEARCH IN PSYCHOTHERAPY, 18, 10-20, ISSN: 2239-8031, doi: DOI: 10.7411/RP.2014.023

Krueger, R.A. (1994). Focus Groups. A Practical Guide for Applied Research. Sage: London.

Liden, R. C., \& Antonakis, J. (2009). Considering context in psychological leadership research. Human Relations, 62(11), 1587-1605.

Mannino, G., Montefiori, V., Faraci, E., Pillitteri, R., Iacolino, C., Pellerone, M. \& Giunta, S. (2017). Subjective Perception of Time: Research Applied on Dynamic Psychology. WORLD FUTURES, 73, 285-302, ISSN: 1556-1844, doi: 10.1080/02604027.2017.1333850

Mannino, G. \& Caronia, V. (2017). Time, Well-Being, and Happiness: A Preliminary Explorative Study. WORLD FUTURES, 318-333, ISSN: 1556-1844, doi: 10.1080/02604027.2017.1333849

Mannino, G. \& Faraci, E. (2017) Morphogenesis of work. application to the psychological well-being and psychosocial health, RISS- Rivista Internazionale di Scienze Sociali, 3, 315-334, ISSN: 978-88-3433431-7, ISSN (carta): 0035-676 X, ISSN (digitale): 1827-7918

Mannino, G. \& Schiera, M. (2017). La famiglia omogenitoriale oggi: pregiudizio per lo sviluppo del minore? Un'analisi della letteratura dal 2000 al 2015. MALTRATTAMENTO E ABUSO ALL'INFANZIA, 19, 87103, ISSN: $1591-4267$

Mannino, G., Giunta, S. \& La Fiura, G. (2017) Psychodynamics of the Sexual Assistance for Individuals with Disability. SEXUALITY AND DISABILITY, 35 (4), 495-506, ISSN: 0146-1044, doi: 10.1007/s11195-017-9491-y

Mannino, G., Giunta, S., Buccafusca, S., Cannizzaro, G., Lo Verso, G. (2015). Communication Strategies in Cosa Nostra: An Empirical Research. WORLD FUTURES, 71, 153-172, ISSN: 1556-1844, doi: $10.1080 / 02604027.2015 .1113770$

Mannino, G. \& Giunta, S (2015). Psychodynamics of the Mafia Phenomenon: Psychological-Clinical Research on Environmental Tapping and White-Collar Crime. WORLD FUTURES, 71, 185-201, ISSN: 1556-1844, doi: 10.1080/02604027.2015.1113774

Matzler, K., Bauer, F. A. \& Mooradian, T. A. (2015). Self-esteem and transformational leadership. Journal of Managerial Psychology, 30(7), 815- 831.

Merton, R. K., Fiske, M., \& Kendall, P.L. (1990). The focused interview: A manual of problems and procedures (2nd ed.). London: Collier MacMillan.

Morgan, D. L. (1997). Focus group as a qualitative research. London: Sage. 
Morgan, D. L. \& Krueger, R.A. (1998). The focus group kit. Sage: Thousand Oaks.

Moscato, G., Novara, C., Hombrados-Mendieta, I., Romano, F. \& Lavanco, G. (2014). Cultural identification, perceived discrimination and sense of community as predictors of life satisfaction among foreign partners of intercultural families in Italy and Spain: A transnational study. International Journal of Intercultural Relations, 40, 22-33. DOI 10.1016/j.ijintrel.2013.11.007

Muhr, T. (1997). Atlas: short user's manual. Scientific Software Development, www.atlasti.de.

Novara, C., Garro, M., Serio, C. \& Cirami, F. (2016a). Co-parenting in Homosexual and Heterosexual Couples: Self-efficacy and Educational Models, International Multidisciplinary Scientific Conferences on Social Sciences and Arts SGEM 2016, BK 1: Psychology and Psychiatry, Sociology and Healthcare, Education Conference Proceedings, I, ISSN 2367-5659.

Novara, C. \& Lavanco, G. (2008). Il setting della ricerca-azione: quadro epistemologico, riflessività e analisi della domanda. Psicologia di comunità, 2, 43-54.

Novara, C., Serio, C. \& Lavanco, G. (2017). Teachers' Representations on Adoptive Families and Educational Practices: New Challenges in Teachers' Preparation. Adoption Quarterly, 20 (2), 135-154. DOI 10.1080/10926755.2016.1201707

Novara, C., Serio, C., \& Moscato, G. (2016b). Unaccompanied foreign minors in the Italian context: From legal order to networking in educational services. Turkish Online Journal of Educational Technology Special Issue for INTE 2016, 1229-1235. Open Access.

Pellerone, M., Iacolino, C., Mannino, G., Formica, I. \& Zabbara, S. (2016). The influence of Parenting on Maladaptive Cognitive Schema: A cross-sectional research on a group of adults. Journal of Psychology Research and Behavior Management, 10, 47-58 DOI: 10.2147/PRBM.S117371.

Samson M. (1999). Training for transformation. Agenda, 41, 6-17. DOI: 10.2307/4066191

Silverman, D. (2013). Doing Qualitative Research: A Practical Handbook (4th ed.). London: Sage.

Venza, G., Novara, C., \& Celi, M. (2007). La scuola dell'autonomia ed i suoi risvolti sul gruppo classe e sul lavoro di gruppo. In G. Venza (a cura di). Dinamiche di gruppo e tecniche di gruppo nel lavoro educativo e formativo. Milano: FrancoAngeli.

Zammuner V.L. (2003). I focus group. Bologna: Il Mulino. 